NASA Technical Memorandum 103705

AIAA-91-0263

\title{
Numerical Simulation of Ice Growth on a MS-317 Swept Wing Geometry
}

M.G. Potapczuk and C.S. Bidwell

Lewis Research Center

Cleveland, Ohio

Prepared for the

29th Aerospace Sciences Meeting

sponsored by the American Institute of Aeronautics and Astronautics Reno, Nevada, January 7-10, 1991

\section{N/Sก}




\title{
Numerical Simulation of Ice Growth on a MS-317 Swept Wing Geometry
}

\author{
M.G. Potapczuk and C.S. Bidwell \\ National Aeronautics and Space Administration \\ Lewis Research Center \\ Cleveland, Ohio 44135
}

\begin{abstract}
$\underline{\text { SUMMARY }}$
An effort to develop a three-dimensional ice accretion modeling method has been initiated. This first step towards creation of a complete aircraft icing simulation code builds on previously developed methods for calculating three-dimensional flowfields and particle trajectories combined with a two-dimensional ice accretion calculation along coordinate locations corresponding to streamlines. This work is intended as a demonstration of the types of calculations necessary to predict a three-dimensional ice accretion. Results of calculations using the 3D method for a MS-317 swept wing geometry are projected onto a $2 \mathrm{D}$ plane parallel to the free stream direction and compared to experimental results for the same geometry. It is anticipated that many modifications will be made to this approach, however this effort will lay the groundwork for future modeling efforts. Results indicate that rime ice shapes predicted by the code agree very well with measured ice shape profiles. Predictions of glaze ice shapes indicate a difficulty in accurately caluculating the ice shape in the runback region.
\end{abstract}

\section{NOMENCLATURE}

$\begin{aligned} \mathrm{A}_{m}= & \text { area that particles impact on the } \\ & \text { surface } \\ \mathrm{A}_{0}= & \text { area through which a group of } \\ & \text { particles travel at release plane } \\ \mathrm{A}_{s}= & \text { control volume surface area } \\ \mathrm{C}_{\mathrm{p}}= & \text { pressure coefficient } \\ \mathrm{C}_{\mathrm{p}_{w}=}= & \text { specific heat of water } \\ \mathrm{d}_{i c e}= & \text { ice thickness } \\ f, \mathrm{FF}= & \text { freezing fraction }\end{aligned}$
h, HTC = convective heat transfer coefficient
$\mathrm{i}, \mathrm{j} \quad=$ grid indices
$\mathrm{L}_{v} \quad=$ latent heat of vaporization
$\dot{\mathrm{m}}_{c} \quad=$ mass flux determined from collection efficiency values
$\dot{\mathrm{m}}_{\mathrm{e}} \quad=$ mass flux evaporating from the surface
$\dot{\mathrm{m}}_{\mathrm{i}} \quad=$ mass flux freezing

Copyright (C) 1991 by the American Institute of Aeronautics and Astronautics, Inc. No copyright is asserted in the United States under Title 17, U.S. Code. The U.S. Government has a royalty-free license to exercise all rights under the copyright claimed herein for Governmental purposes. All other rights are reserved by the copyright owner. 


\begin{tabular}{|c|c|c|c|c|c|}
\hline$\dot{\mathrm{n}}_{\mathbf{r}_{\text {in }}}$ & $=$ & $\begin{array}{l}\text { runback mass flux from the } \\
\text { previous control volume }\end{array}$ & $\begin{array}{l}\mathrm{T}_{\mathrm{s}}, \mathrm{TS} \\
\mathrm{T}_{\infty}\end{array}$ & $\begin{array}{l}= \\
=\end{array}$ & $\begin{array}{l}\text { temperature at the surface } \\
\text { temperature in the free stream }\end{array}$ \\
\hline$\dot{\mathrm{m}}_{\mathrm{r}_{\text {out }}}$ & $=$ & $\begin{array}{l}\text { mass flux into the downstream } \\
\text { control volume }\end{array}$ & $\mathrm{t}$ & $\begin{array}{l}= \\
=\end{array}$ & $\begin{array}{l}\text { time } \\
\text { weighting factor in } \mathrm{j} \text {-direction }\end{array}$ \\
\hline$\dot{\mathrm{q}}_{\mathrm{c}}$ & $=$ & $\begin{array}{l}\text { heat flux due to the impacting } \\
\text { water droplets }\end{array}$ & $\begin{array}{l}\mathrm{VE} \\
\mathrm{V}_{\infty}\end{array}$ & $\begin{array}{l}= \\
=\end{array}$ & $\begin{array}{l}\text { local inviscid velocity } \\
\text { free-stream velocity }\end{array}$ \\
\hline$\dot{\mathrm{q}}_{\text {cond }}$ & $=$ & $\begin{array}{l}\text { heat flux due to conduction } \\
\text { through the ice/airfoil surface }\end{array}$ & $\begin{array}{l}\mathrm{v} \\
\mathrm{W}\end{array}$ & $\begin{array}{l}= \\
=\end{array}$ & $\begin{array}{l}\text { weighting factor in i-direction } \\
\text { unit width in spanwise direction }\end{array}$ \\
\hline $\begin{array}{l}\dot{\mathrm{q}}_{\text {conv }} \\
\dot{\mathrm{q}}_{\text {evap }}\end{array}$ & $\begin{array}{l}= \\
=\end{array}$ & $\begin{array}{l}\text { heat flux due to convection } \\
\text { heat flux due to evaporation }\end{array}$ & $\overrightarrow{\mathrm{X}}_{\mathrm{i}}$ & $=$ & $\begin{array}{l}\text { displacement vector from } x(i, j) \text { to } \\
x(i+1, j)\end{array}$ \\
\hline$\dot{\mathrm{q}}_{\mathrm{i}}$ & $=$ & $\begin{array}{l}\text { heat flux required for phase } \\
\text { change of water to ice }\end{array}$ & $\overrightarrow{\mathrm{X}}_{\mathrm{j}}$ & $=$ & $\begin{array}{l}\text { displacement vector from } x(i, j) \text { to } \\
x(i, j+1)\end{array}$ \\
\hline$\dot{\mathrm{q}}_{\mathrm{r}_{i n}}$ & $=$ & $\begin{array}{l}\text { heat flux associated with the } \\
\text { incoming runback water }\end{array}$ & $\overrightarrow{\mathrm{X}}_{s}$ & $=$ & $\begin{array}{l}\text { displacement vector from } \mathrm{x}(\mathrm{i}, \mathrm{j}) \text { to } \\
\mathrm{x}_{\boldsymbol{s}}\end{array}$ \\
\hline$\dot{\mathrm{q}}_{\mathrm{r}}$ out & $=$ & $\begin{array}{l}\text { heat flux associated with the } \\
\text { outgoing runback water }\end{array}$ & $\begin{array}{l}\mathrm{x}_{s} \\
\mathrm{x}_{c}\end{array}$ & $\begin{array}{l}= \\
=\end{array}$ & $\begin{array}{l}\text { location along surface streamline } \\
\text { location of centroid of } A_{m}\end{array}$ \\
\hline $\operatorname{Re}$ & $=$ & Reynolds number & $\beta, \mathrm{BETA}$ & $=$ & collection efficiency \\
\hline S & $=$ & surface & $\gamma$ & $=$ & sweep angle \\
\hline $\mathrm{s}$ & $=$ & surface distance & $\rho$ & $=$ & density \\
\hline $\mathrm{s}_{c}$ & $=$ & chordwise component of $\mathrm{s}$ & & & \\
\hline
\end{tabular}

\section{Introduction}

Ice accretion modeling has received considerable attention during the past few years. The National Aircraft Icing Technology Plan ${ }^{1}$, drafted in 1986 under the direction of several federal agencies, calls for the creation of a complete aircraft icing simulation during the coming decade. In support of this plan several activities related to the creation of a $2 \mathrm{D}$ ice accretion modeling and performance evaluation capability have been undertaken at the NASA Lewis Research Center. A 2D ice accretion code, LEWICE, was developed in 1983 by the University of Dayton Research Institute ${ }^{2}$ and later modified by Ruff ${ }^{3}$. This code is divided into three major parts; a potential flow calculation, a particle trajectory calculation, and an ice growth calculation. The ability of LEWICE to predict airfoil ice accretions is quite good for rime ice growths. Glaze ice predictions, although acceptable, have exhibited some deficiencies which have been documented by several authors ${ }^{4-6}$. The calculation of performance degradation due to icing is an equally important aspect of the icing analysis problem. Over the past several 
years 2D calculations for iced airfoils have been performed using the interactive boundary layer $\operatorname{method}^{7}$ and using Navier-Stokes $\operatorname{codes}^{8}$. Recently, Cebeci ${ }^{9}$ has combined his interactive boundary layer method with LEWICE. This has resulted in a code which has the potential to accurately determine the flowfield and particle trajectories while also providing the performance degradation information during a single calculation.

With these activities firmly underway, it is appropriate to consider the methodology for development of a three-dimensional ice accretion analysis capability. Some of the issues associated with a 3D icing calculation are the same as those for 2D. On the other hand, some issues only become evident when considering a full 3D calculation. These may include; variations in ice growth on both a large and small scale across a wing span, runback in the spanwise direction, non-uniformities in the impinging cloud along the span, and particle trajectories in complex geometric regions.

The current effort is directed at taking existing computer codes and developing a strategy for performing a 3D ice accretion and performance degradation calculation for a swept wing configuration. This activity will serve as a demonstration calculation and as a focus for future development of the approach. The computer codes used in this effort consist of a 3D panel code, a 3D particle trajectory code, and the ice accretion subroutines of the 2D LEWICE code. The performance calculations will use a 3D Navier-Stokes code, ARC3D. Presently, the ice accretion and performance calculations are performed separately. In the future, these calculations will be performed in a single code thus requiring less user interaction than is currently necessary.

This report addresses only the ice accretion aspects of the 3D problem. It documents the first attempt at comparison of 3D ice accretion calculations to measured ice shape tracings. The wing geometry chosen for this calculation is that of an MS-317 airfoil with a $30^{\circ}$ sweep angle, as shown in Figure 1. As indicated in the figure, the MS-317 profile was maintained in the direction parallel to the free stream velocity and not in the direction perpendicular to the leading edge. The MS-317 airfoil model represents a typical medium-speed wing section. The ice tracings were taken from a swept MS-317 airfoil model which was subjected to a range of icing conditons in the NASA Lewis Icing Research Tunnel. The details of the test procedure are outlined in reference 10 . 
A 3D ice accretion calculation for a complete aircraft is a major step forward from current capabilities. The present activity is directed at extending current 2D capabilities to simple 3D geometries by assuming constant spanwise gradients. For this work, an infinite swept wing of constant geometry in the spanwise direction is used. Such a geometry produces similar streamlines along the span. As a result of this streamline similarity, it is assumed that there is no net transport of water across the control volume in the spanwise direction. The control volume analysis of the ice accretion can thus be considered two dimensional and the 2D LEWICE routines can be used. This also allows a single evaluation of the ice growth for any streamline to represent the ice accretion behavior for any location on the wing. Since the resulting ice shape geometry will not vary along the span, re-paneling of the iced wing for subsequent ice accretion calculations is simplified.

An infinite swept wing also avoids consideration of ice growth near the tip of the wing or at the wing-body junction. At these locations, the flowfield is quite irregular and major changes to the approach currently being employed would be required. It is anticipated that future work in $3 \mathrm{D}$ ice accretion prediction would be directed at addressing these regions of the flowfield. Currently, the tools necessary for evaluation of these complex flowfields are being developed by Sankar ${ }^{11}$ and Caruso ${ }^{12}$ with funding from NASA Lewis. Additional work will be required to create a 3D control volume analysis for the ice accretion calculation. As these codes become available, they will be incorporated into the 3D ice accretion analysis methodology.

\section{II-1. 3D Panel Code and Particle Trajectory Calculation}

The flowfield and particle trajectory calculations are extensions of the 2D analysis methods used in LEWICE. The three-dimensional flowfield calculation uses a Hess-Smith panel code ${ }^{13}$. The code can accomodate lifting and non-lifting geometries or combinations, thus allowing simulation of complex surfaces such as a complete aircraft. A Prandtl-Glauert correction is used to allow compressible flow calculations. The code can also handle leaking panels to simulate inlets or instrument orifices. The code provides velocity information at any point in the flowfield away from the surface. This type of code uses very little computer time compared to a viscous flow code and yet provides sufficient flowfield information for subsequent trajectory and energy balance calculations under most circumstances. 
The trajectory calculation is based on the computer code developed by Norment ${ }^{14}$ with one additional feature. The code solves a force balance equation on a single particle and then determines the new particle position using an Adams-type predictor-corrector algorithm developed by $\mathrm{Krogh}^{15}$. The added feature is the ability to calculate the local collection efficiency from the impacting particles. The code generates an array of impingement points for each region of interest. This is done by releasing an array of particles which impact the region of interest (Figure 2). The collection efficiency is the ratio of the particle flux at the target point to the free-stream particle flux. If a known group of particles is tracked from their release location to the target location, then the collection efficiency can be determined by the ratio of the target area to the release area. The collection efficiency can then be determined from the following relationship,

$$
\beta\left(\mathrm{x}_{c}(\mathrm{i}, \mathrm{j})\right)=\mathrm{A}_{o}(\mathrm{i}, \mathrm{j}) / \mathrm{A}_{m}(\mathrm{i}, \mathrm{j})
$$

Once the collection efficiency is determined for the surface, an array of surface locations and corresponding $\beta$ values is created for streamlines on the surface. This information will be used in the ice accretion calculation to determine ice growth along the streamline paths. The streamlines are calculated using a 4th order Runge-Kutta integration scheme. The streamline is carried forward from the stagnation region for both the upper and lower surface at the region of interest.

A linear interpolation scheme is used to determine the collection efficiency along the streamline from the matrix of $\beta$ values generated in the trajectory calculation. The array of $\beta$ values is searched to find the surface cell in which the streamline point resides (Figure 3). The $\beta$ value at the streamline point is then determined from a weighted average of the local collection efficiencies at the four surrounding cell points. The interpolation expression is,

$$
\begin{aligned}
\beta\left(\mathrm{x}_{s}\right) \simeq & \beta\left(\mathrm{x}_{c}(\mathrm{i}+1, \mathrm{j}+1)\right) \cdot \mathrm{u} \cdot \mathrm{v}+\beta\left(\mathrm{x}_{c}(\mathrm{i}, \mathrm{j}+1)\right) \cdot \mathrm{u} \cdot(1-\mathrm{v})+\beta\left(\mathrm{x}_{c}(\mathrm{i}, \mathrm{j})\right) \cdot(1-\mathrm{u}) \cdot(1-\mathrm{v}) \\
& +\beta\left(\mathrm{x}_{c}(\mathrm{i}+1, \mathrm{j})\right) \cdot(1-\mathrm{u}) \cdot \mathrm{v}
\end{aligned}
$$

where,

$$
\mathrm{u}=\overrightarrow{\mathrm{X}}_{\mathrm{s}} \cdot \overrightarrow{\mathrm{X}}_{\mathrm{j}}
$$


and

$$
\mathrm{v}=\overrightarrow{\mathrm{X}}_{s} \cdot \overrightarrow{\mathrm{X}}_{\mathrm{i}}
$$

represent weighting factors in the interpolation based on the geometry of the cell.

\section{II-2. Ice Accretion Calculation}

The ice accretion calculation is performed as a $2 \mathrm{D}$ strip analysis along streamlines calculated by the $3 \mathrm{D}$ panel code. The results of the previous calculation are written into a file containing the $x, y, z$ coordinates of the streamline, the surface distance between points, the $\mathrm{x}, \mathrm{y}, \mathrm{z}$ components of the unit normal vector for the panel at the streamline coordinate locations, the velocities, and the local collection efficiencies, $\beta$. The subroutines from the LEWICE code which determine the boundary layer values, the control volume energy balance and the resulting ice growth are used to determine the ice shape at a given spanwise location. A brief outline of the LEWICE calculation follows. Further details can be found in reference 3 .

The ice accretion calculation consists of a control volume mass and energy balance. The $2 \mathrm{D}$ strip analysis allows use of the assumption that there are no spanwise fluxes into the control volume, which is consistant with the infinite swept wing flowfield assumption. A depiction of the control volume for the process is shown in Figure 4. The $\Delta s$ value is based on distance along the streamline. The surface area covered by the control volume consists of a parallelogram and is given by,

$$
\mathrm{A}_{s}=\Delta \mathrm{s}_{c} \mathrm{~W}
$$

where $\Delta \mathrm{s}_{c}$ is the component of the segment length in the chordwise direction and $\mathrm{W}$ is the width of the segment in the spanwise direction. A series of these control volumes are stacked along the streamline starting at the leading edge of the wing.

The mass balance equation is,

$$
\dot{\mathrm{m}}_{\mathrm{C}}+\dot{\mathrm{m}}_{\mathrm{r}_{\text {in }}}=\dot{\mathrm{m}}_{\mathrm{e}}+\dot{\mathrm{m}}_{\mathrm{r}_{\text {out }}}+\dot{\mathrm{m}}_{\mathrm{i}}
$$

The impinging mass flux, $\dot{\mathrm{m}}_{\mathrm{C}}$, is determined from the $\beta$ distribution. The mass flux into the control volume, $\dot{\mathrm{m}}_{\mathrm{r}_{i n}}$, is any water remaining in the liquid state after evaluation of an upstream control volume. This mass flux is called runback. The mass flux out of the control volume due to evaporation, $\dot{\mathrm{m}}_{\mathrm{e}}$, and to freezing, $\dot{\mathrm{m}}_{\mathrm{i}}$, are 
determined from the energy balance calculations. The mass flux out of the control volume, $\dot{\mathrm{m}}_{\mathrm{r}_{\text {out }}}$, is used as input for the downstream control volume. The freezing fraction is a term used to describe the fraction of incoming liquid that freezes within the control volume. It is given by the expression,

$$
f=\frac{\dot{\mathrm{m}}_{\mathrm{i}}}{\dot{\mathrm{m}}_{\mathrm{c}}+\dot{\mathrm{m}}_{\mathrm{r}_{\text {in }}}}
$$

The energy balance equation is,

$$
\dot{\mathrm{q}}_{\mathrm{c}}+\dot{\mathrm{q}}_{\mathrm{r}_{\text {in }}}=\dot{\mathrm{q}}_{\text {cond }}+\dot{\mathrm{q}}_{\text {evap }}+\dot{\mathrm{q}}_{\text {conv }}+\dot{\mathrm{q}}_{\mathrm{r}_{\text {out }}}+\dot{\mathrm{q}}_{\mathrm{i}}
$$

The values of $\dot{\mathrm{q}}_{\mathrm{C}}$ and $\dot{\mathrm{q}}_{\mathrm{r}_{i n}}$ are obtained from mass flux values and the internal energy levels of the incoming water. Integral boundary layer expressions are used to determine the heat flux due to convection. The inviscid flowfield values are used as boundary values for the viscous calculation. The boundary layer calculation determines the location of transition from laminar to turbulent flow and then uses an appropriate value of the convection heat transfer coefficient. The heat transfer value is then obtained by use of Newton's law of cooling,

$$
\dot{\mathrm{q}}_{\text {conv }}=\mathrm{h} \mathrm{A}_{s}\left(\mathrm{~T}_{s}-\mathrm{T}_{\infty}\right)
$$

The evaporative heat flux is also obtained from consideration of the inviscid flowfield conditions using the expression,

$$
\dot{\mathrm{q}}_{\text {evap }}=\dot{\mathrm{m}}_{\mathrm{e}}\left(\mathrm{C}_{\mathrm{p}_{w, s}} \mathrm{~T}_{s}+\mathrm{L}_{v}\right) \Delta \mathrm{s}
$$

where the evaporative mass transfer rate, $\dot{\mathrm{m}}_{\mathrm{e}}$, is determined from local pressure, temperature, and humidity conditions. Further details on this calculation are found in reference 3. The heat flux due to conduction is a user specified value. This leaves two equations for the two unknowns, $\dot{\mathrm{m}}_{\mathrm{r}_{\text {out }}}$ and $\dot{\mathrm{m}}_{\dot{j}}$.

The mass of ice that freezes is used to determine the thickness of the resulting ice layer. Since the analysis is locally $2 \mathrm{D}$, the ice thickness can be found from the relation,

$$
\mathrm{d}_{i c e}=\frac{\dot{\mathrm{m}}_{\mathrm{i}} \Delta \mathrm{t}}{\rho_{\text {ice }} \Delta \mathrm{s}_{c} \mathrm{~W}}
$$


The thickness is then considered to be uniform over the entire panel for subsequent flowfield calculations. The new coordinates for the panel are obtained from the relation,

$$
\mathrm{x}_{i}=\mathrm{x}_{i}+\mathrm{d}_{i c e} \hat{\mathrm{x}}_{i}
$$

where $\mathrm{x}_{i}$ is the coordinate of the center of the panel in the $i$-direction and $\hat{\mathrm{x}}_{i}$ is the $i$-component of the unit normal vector for the panel.

As the ice thickness increases, there is the possibility that ice segments will intersect and thus this must be accounted for in the determination of the new geometry. Since this is a strip analysis, the ice thickness does not vary along the span at a given chordwise location. Therefore, the possibility of ice growth intersection is limited to the normal and chordwise directions. In that case, the line segments corresponding to the top of every other panel are examined for intersection. If intersection is determined to occur, then a new panel is formed with its center halfway between the two old panels. This requires determination of the coordinates of the new panel and renumbering of the panels. This information is then used in subsequent potential flow calculations.

The ice shapes developed from the current calculations are based on a single time step. This was done to limit the number of particle trajectory calculations in favor of evaluating a larger number of icing conditions. The results, described in section IV, indicate that for short icing encounters the code compared well with experiment while for longer icing encounters time stepping may be required. In such cases, the output geometry file of the code is in the appropriate format for development of new surface panels. The updated geometry would then be used in a recalculation of the flowfield, particle trajectories, and ice growth.

\section{MS-317 Ice Shape Tracings}

The MS-317 airfoil used to generate ice shape tracings for a swept wing configuration is shown in figure 5. This model was created specifically to produce ice shapes for code validation purposes. As such, it was designed with a constant MS-317 profile in the flowfield direction at every spanwise location, as opposed to a constant MS-317 profile perpendicular to the leading edge. This means that the chord of the airfoil is in the direction parallel to the tunnel walls and not perpendicular to the leading edge. The wing was also a full-span model in order to avoid the complications of tip effects on the ice growth patterns. The icing conditions tested, listed in Table 1, cover a range from glaze to rime conditions with velocities appropriate for a mediumspeed airfoil. 
Ice shape profiles were documented by cutting a slice in the accreted ice, parallel to the free stream flow direction, and tracing the ice profile onto a template. The cut in the ice shape was made at the mid-span location to ensure that end effects were eliminated and that cloud uniformity was maximized. The tracings were then digitized for use in plotting the profile and for comparison to predicted ice shapes.

Since ice shapes were traced at only one spanwise location, the variability of the accreted ice in the spanwise direction is not documented quantitatively. Photographs of the ice accretions were taken however, as seen in the examples shown in figure 6 , and they indicate a high degree of uniformity along the span in terms of ice mass and icing extent in the chordwise direction. There is however, considerable spanwise variation in the ice shape profiles. This type of variation in ice shapes has been documented in previous studies ${ }^{16}$ and is demonstrated in figure 7. Also, the variation in chordwise extent of the ice is seen in the rime ice accretion photograph. This localized ice shape variability essentially precludes exact reproduction of an ice shape by any ice accretion calculation method. Instead, the code should be able to reproduce major features of the ice accretion, such as mass of the accreted ice as measured by the cross-sectional area, ice thickness at corresponding locations along the surface, presence or absence of horns, and average chordwise extent of the accretion.

\section{Code Prediction/Tracing Comparisons}

The ice shapes were accreted at $2^{\circ}$ and $8^{\circ}$ angle of attack. The calculated pressure coefficient plots for those conditions are shown in figure 8. The plots show the large suction peak at the high angle of attack condition, which can alter trajectories of smaller droplets and tends to freeze out any water impinging on that surface due to the enhanced heat transfer. The relatively flat pressure distribution on the lower surface does not significantly alter droplet trajectories and allows greater runback on the lower surface.

The calculated local collection efficiencies for the two angle of attack conditions are shown in figure 9. These results are for a droplet size of $20 \mu \mathrm{m}$. The results indicate the reduced overall impingement at $8^{\circ}$ and the shifting of the impingement pattern to the lower surface. The plots indicate that there is no impingement on the upper surface for the $8^{\circ}$ angle of attack condition. Any calculated ice growth on the upper surface is therefore a result of freezing of runback water. These calculations are for a $2 \mathrm{D}$ cut along the flow direction. 
The rime ice conditions correspond to the runs at $0^{\circ} \mathrm{F}$ (i.e. runs $8-11$ ). The overall features of these ice shapes were reproduced very well by the calculations, as seen in figures 10-13. This is indicated by the impingement limit locations, which correspond to the ice limits for a rime ice growth, and by the cross-sectional area of the ice shape. Since water freezes on impact for rime ice cases, these results suggest that the flowfield, droplet trajectory, and ice growth routines are working well. The results also indicate closer agreement for the 6 minute results than for the 19.4 minute results. Since the code was run with only one time step for both cases, the changes in the flowfield due to the ice shape growth were not reflected in the collection efficiency or heat transfer calculations. Multiple time step calculations should be performed to try to improve the agreement between code and experiment.

Mixed glaze and rime ice growths resulted from the conditions used in runs 1, 6, and 7. The comparisons are shown in figures 14-16. Once again, the agreement was much better for the shorter icing time. The $\alpha=8^{\circ}$ case, as shown in figure 16, indicates that the measured ice shape appeared to grow upstream as opposed to normal to the surface. The changes in collection efficiency distribution due to the development of the ice may be favoring growth in that direction. This interaction of changing particle impingement patterns with ice growth is not be accounted for by use of a single time step calculation.

The runs at $28^{\circ} \mathrm{F}$ represent glaze ice accretions. These are characterized by clear ice, growth of horns, and runback water freezing aft of the impingement limits. Typical results are shown in figures 17-20. As seen, the calculations produce a shape that indicates a somewhat larger amount of runback than is evident from the actual ice growth. The calculation did not result in development of horns, which is due to the interaction of collection efficiency changes and runback. However, the overall growth patterns of the ice were reproduced quite well.

The variability in ice shapes between two runs at the same condtions can be as great as the differences between measured and calculated shapes. This is due partly to uncertainty in the repeatability of set conditions in the actual cloud and partly to the spanwise variation of a given accretion. Figure 21 indicates this variability by comparing tracings at the same spanwise locations from two separate runs (i.e. runs 2 and 13), nominally at the same conditions, to a calculated accretion. The measured shapes have a larger amount of total mass, most likely due to the increase in total collection efficiency for the actual accretion not accounted for by the single time step approach used in the calculation. On the basis of profile alone however, the calculated 
shape more closely resembles the tracing from run 13 than that from run 2. This figure suggests that there may be little gained by trying to fine tune the ice accretion code beyond the point of determining the overall mass, whether it is rime or glaze, and the size and direction of glaze horns. The end product of the calculations, whether ice shape or performance degradation information, will also determine the degree of fidelity required from a given ice accretion calculation.

The most influential parameter for glaze ice accretions, after the collection efficiency, is the roughness. The LEWICE roughness parameter establishes a roughness level used in the boundary layer calculations which is based on the liquid water content, velocity, and temperature of the cloud and the base surface roughness level of the wing. This roughness parameter was obtained from a correlation of these parameters with calculated ice shapes which compared well with measured ice shapes. This correlation was developed by Ruff and is described in the LEWICE user's manual. ${ }^{3}$ As the result of a series of calculations with different roughness levels, a roughness parameter a factor of four larger than the values suggested in the manual was found to produce better agreement with experiment and was used consistently throughout the course of this investigation. The need for a larger roughness value could be due to the spanwise flow and its effect on the heat transfer coefficient. Enhanced heat transfer due to this component of the flow would result in more rapid freezing and less runback than for two-dimensional airfoil models, from which the LEWICE correlations were derived. Thus, a new set of correlation equations may be required for ice accretion calculations on 3D geometries. This could prove a challenging task for more complicated geometries such as wing-body junctions.

\section{Conclusions}

A 3D ice accretion code has been developed which calculates the 3D flowfield, 3D particle trajectories, and ice growth along 2D strips on the surface of interest. Comparisons to actual ice shape tracings indicate that the methods used in the $2 \mathrm{D}$ LEWICE code should be capable of being extended to evaluation of 3D ice growth. The single time step calculations used for this investigation were able to reproduce the overall characteristics of the ice shapes quite well. Extension to a time stepping proceedure, as in the 2D code, should be investigated to determine if the ice horn growth for glaze ice conditions can be more accurately reproduced.

The approach employed in this investigation is applicable to infinite swept-wing geometries. This approach should also be adequate, considering all the uncertainties in 
ice accretion calculations, in regions on the wing away from the root or tip, where spanwise gradients are not severe. Rime ice conditions, where water freezes on impact and the determination of flow direction of runback water is not required, should also be capable of being predicted using this approach. However, in regions where the flowfield is very complex and under conditions where runback may occur, a different approach may be required to evaluate the development of glaze ice accretions. This could be quite significant for the evaluation of wing tips and outboard sections of rotor blades.

The development of new heat transfer correlations may also be required if the $2 \mathrm{D}$ LEWICE methodology is to be extended to 3D glaze ice calculations. This would require the evaluation of ice accretion from several 3D wing models, in order to increase the confidence level in the code to that of 2D LEWICE. Additionally, some method of characterizing the spanwise variation of ice growth on a 3D geometry must be developed. This would allow more comparisons to code for a given icing experiment and indicate the degree of accuracy to which the code can be reasonably expected to conform.

\section{Acknowledgement}

The authors would like to acknowledge the assistance of Ms. Ivy Wu in preparation of the digitized data files from the ice shape tracings. 


\section{REFERENCES}

1. National Aircraft Icing Technology Plan, Federal Coordinator for Meteorological Services and Supporting Services, Department of Commerce, FCM-P20-1986, April 1986.

2. MacArthur, C.D., Keller, J.L., and Leurs, J.K., "Mathematical Modeling of Ice Accretion on Aerofoils," AIAA-82-0284, 1982.

3. Ruff, G.A. and Berkowitz, B.M., "Users Manual for the NASA Lewis Ice Accretion Prediction Code (LEWICE)," NASA CR-185129, May 1990.

4. Berkowitz, B.M. and Riley, J.T., "Analytical Ice Shape Predictions for Flight in Natural Icing Conditions," NASA CR-182234, 1989.

5. Hansman, R.J., Yamaguchi, K., Berkowitz, B., and Potapczuk, M.G., "Modeling of Surface Roughness Effects on Glaze Ice Accretion," AIAA Paper 89-0734, Jan. 1989.

6. Riley, J.T., "Uncertainty and Error Prpoagation in Aircraft Icing Calculations," AIAA Paper 90-0760, Jan. 1990.

7. Cebeci, T., "Prediction of Flow Over Airfoils with Leading Edge Ice," AIAA Paper 88-0112, Jan. 1988.

8. Potapczuk, M.G., "Navier-Stokes Analysis of Airfoils with Leading Edge Ice Accretions," PhD Dissertation, The University of Akron, May 1989.

9. Cebeci, T., Chen, H.H., and Alemdaroglu, N., "Fortified LEWICE with Viscous Effects," AIAA Paper 90-0754, Jan. 1990.

10. Bidwell, C.S., "Icing Characteristics of a Natural Laminar Flow, a Medium-Speed, and a Swept Medium-Speed Airfoil," AIAA Paper 91-0447, Jan. 1991.

11. Kwon, O. and Sankar, L.N., "Numerical Study of the Effects of Icing on Finite Wing Aerodynamics," AIAA Paper 90-0757, Jan. 1990. 
12. Caruso, S.M., "Development of an Unstructured Mesh/Navier-Stokes Method for Aerodynamics of Aircraft with Ice Accretions," AIAA Paper 90-0758, Jan, 1990.

13. Hess, J.L. and Smith, A.N.O., "Calculation of Potential Flow About Arbitrary Bodies," Progress in Aeronautical Sciences, Vol. 8, edited by D. Kuchemann, Pergammon Press, New York, 1967.

14. Norment, H.G., "Calculation of Water Drop Trajectories to and about Arbitrary Three-Dimensional Lifting and Nonlifting Bodies in Potential Airflow, NASA CR 3935, Oct. 1985.

15. Krogh, F.T., "Variable Order Integrators for Numerical Solutions of Ordinary Differential Equations," Jet Propulsion Lab Technology Utilization Document No. CP-2308, Nov. 1970.

16. Potapczuk, M.G. and Berkowitz, B.M., "Experimental Investigation of Multielement Airfoil Ice Accretion and Resulting Performance Degradation," Journal of Aircraft, Vol. 27, No. 8, August 1990, pp. 679-691. 
Table I : Test conditions for MS-317 Ice Accretion Experiment

\begin{tabular}{|c|c|c|c|c|c|c|c|}
\hline Run & $\begin{array}{c}\mathrm{T} \\
\left({ }^{\circ} \mathrm{F}\right)\end{array}$ & $\begin{array}{c}\mathrm{V} \\
(\mathrm{mph})\end{array}$ & $\begin{array}{c}\mathrm{d} \\
(\mu \mathrm{m})\end{array}$ & $\begin{array}{c}\mathrm{LWC} \\
\left(\mathrm{g} / \mathrm{m}^{3}\right)\end{array}$ & $\begin{array}{c}\mathrm{t} \\
(\mathrm{sec})\end{array}$ & $\begin{array}{c}\alpha \\
(\mathrm{deg})\end{array}$ & $(\mathrm{k} / \mathrm{c})_{i}$ \\
\hline 1 & 15 & 150 & 20 & 1.03 & 1164 & 2.0 & 0.00192 \\
2 & 28 & 150 & 20 & 1.03 & 1164 & 2.0 & 0.00931 \\
3 & 28 & 150 & 20 & 1.03 & 390 & 2.0 & 0.00931 \\
4 & 28 & 150 & 20 & 1.03 & 1164 & 8.0 & 0.00931 \\
5 & 28 & 150 & 20 & 1.03 & 390 & 8.0 & 0.00931 \\
6 & 15 & 150 & 20 & 1.03 & 1164 & 8.0 & 0.00192 \\
7 & 15 & 150 & 20 & 1.03 & 390 & 2.0 & 0.00192 \\
8 & 0 & 150 & 20 & 1.03 & 390 & 2.0 & 0.00127 \\
9 & 0 & 150 & 20 & 1.03 & 390 & 8.0 & 0.00127 \\
10 & 0 & 150 & 20 & 1.03 & 1164 & 8.0 & 0.00127 \\
11 & 0 & 150 & 20 & 1.03 & 1164 & 2.0 & 0.00127 \\
12 & 28 & 150 & 12 & 0.43 & 918 & 2.0 & 0.00931 \\
13 & 28 & 150 & 20 & 1.03 & 1164 & 2.0 & 0.00931 \\
14 & 0 & 150 & 12 & 0.43 & 2760 & 2.0 & 0.00127 \\
15 & 0 & 150 & 12 & 0.43 & 2760 & 0.0 & 0.00127 \\
\hline
\end{tabular}




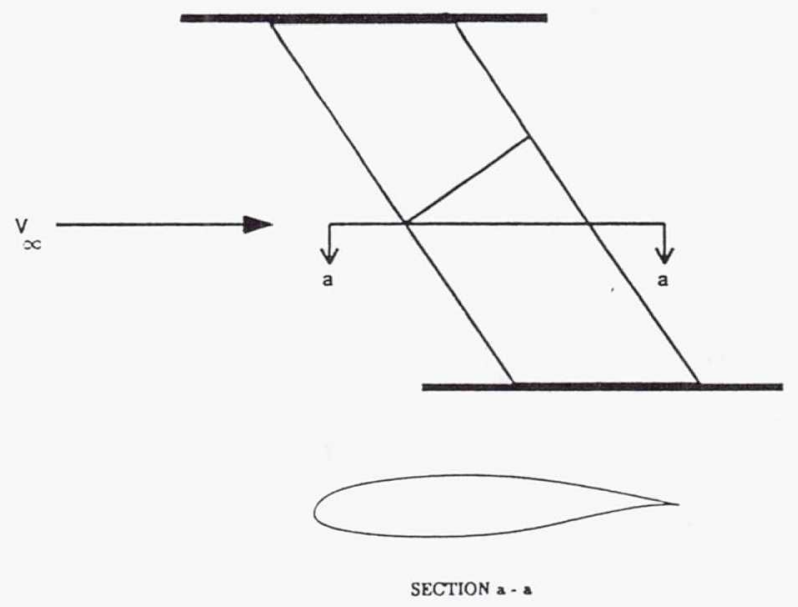

FIGURE 1. - MS-317 SWEPT WING PROFILE.

$\phi \equiv$ impingement point array $\left[x_{m}(I, J)\right]$

$-\alpha-$ starting point array $\left[x_{0}(I, J)\right]$

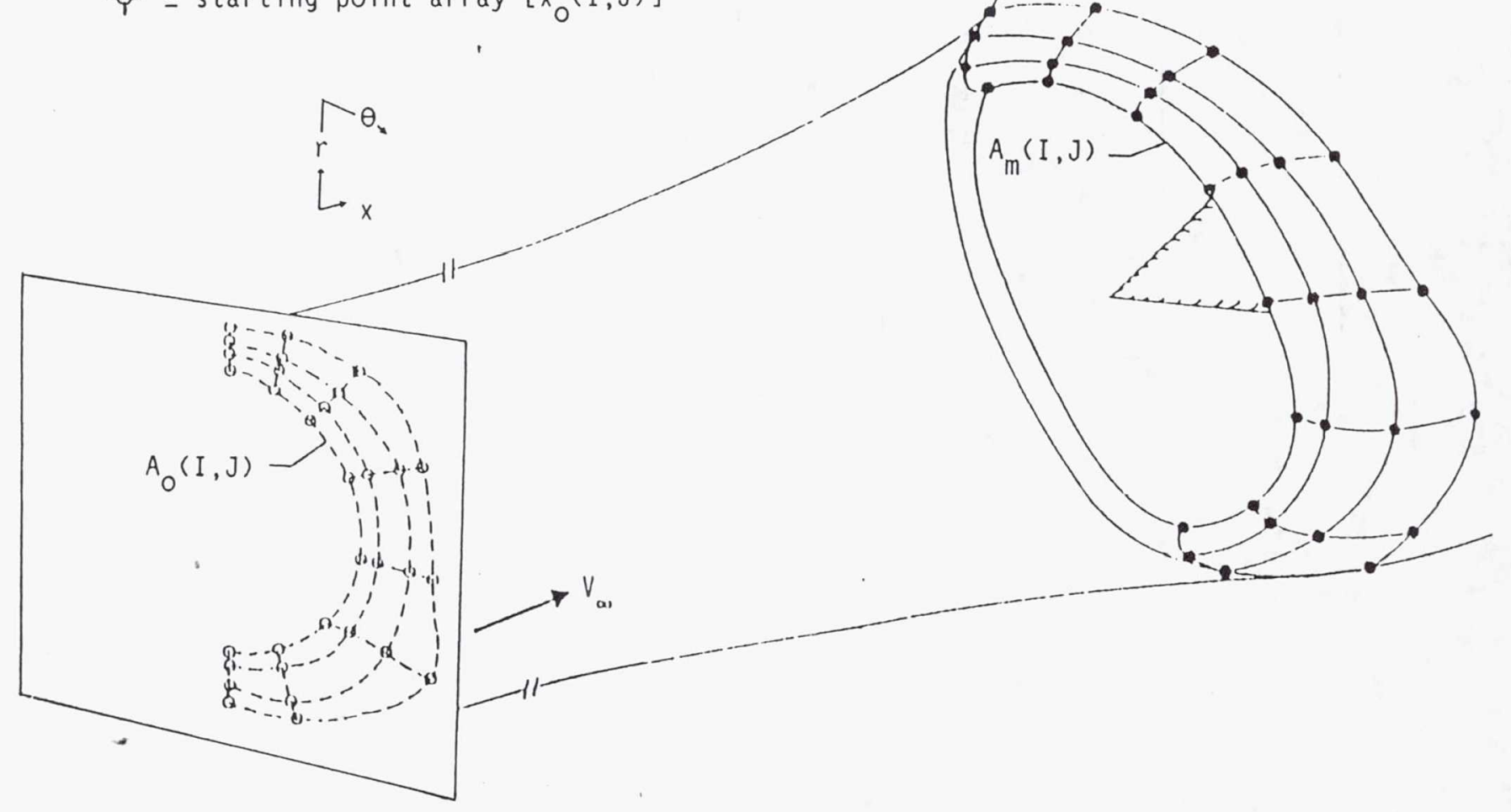

FIGURE 2. - ILLUSIRATION OF THE STARTING POINT ARRAY $\left[x_{0}(I, J)\right]$ AND IMPINGEMENT POINT ARRAY $\left[x_{m}(1, J)\right]$. 

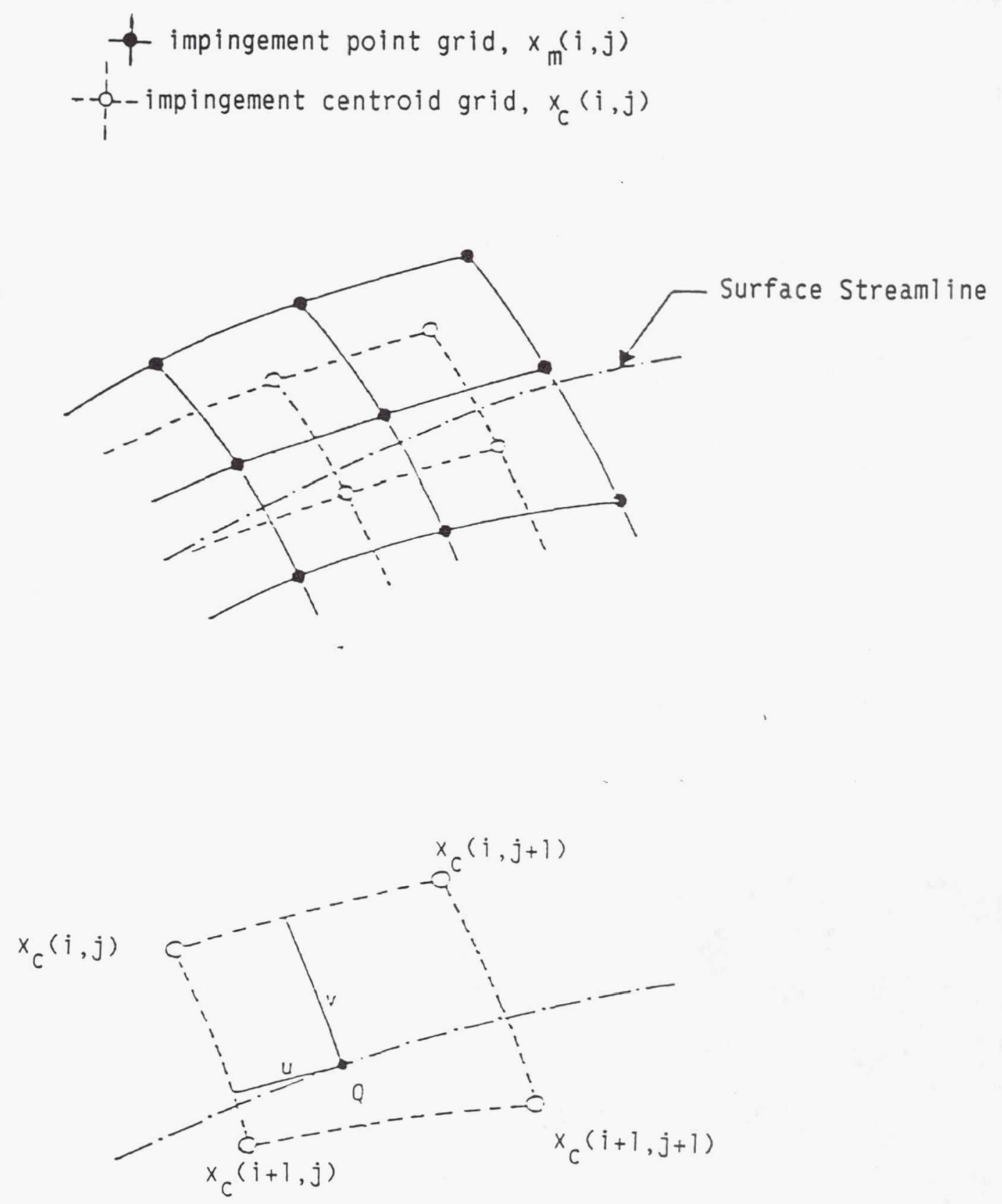

$$
\begin{aligned}
\beta(Q) \cong \beta\left(x_{C}(i+1, j+1)\right) \cdot u \cdot v & +\beta\left(x_{C}(i, j+1)\right) \cdot u \cdot(1-v)+\beta\left(x_{C}(i, j)\right) \cdot(1-u) \cdot(1-v) \\
& +\beta\left(x_{C}(i+1, j)\right) \cdot(1-u) \cdot v
\end{aligned}
$$

FIGIIRE 3. - ILLUSTRATION OF THE CENTROID IMPINGEMENT GRID $\left[\mathrm{s}_{\mathrm{C}}(1, \mathrm{~J})\right]$ AND $\beta$ INTERPOLATION. 


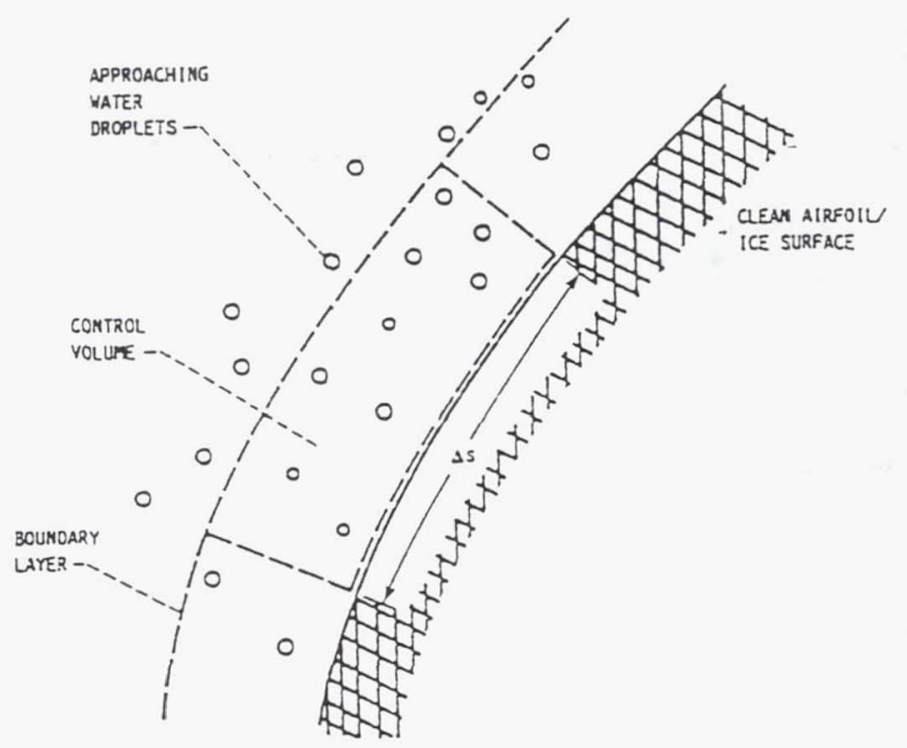

FIGURE 4. - CONTROL VOLUME FOR ICE ACCRETION CALCULATION.

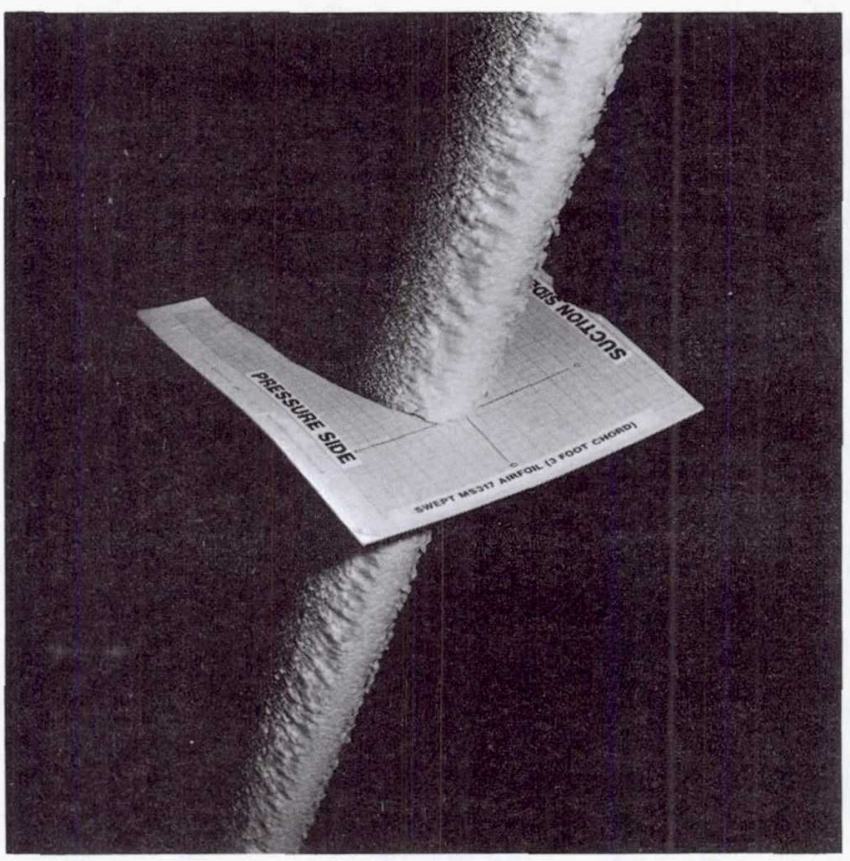

(a) RIME ICE AT $0^{0} \mathrm{~F}$ AND $a=2^{0}$, RUN NO, $8 \mathrm{~B}$. FIGURE 6. - TYPICAL ICE ACCRETION ON MS-317 MODEL. TRACING OF ICE SHAPE WAS MADE FROM CUT PARALLEL TO THE FLOW DIRECTION.

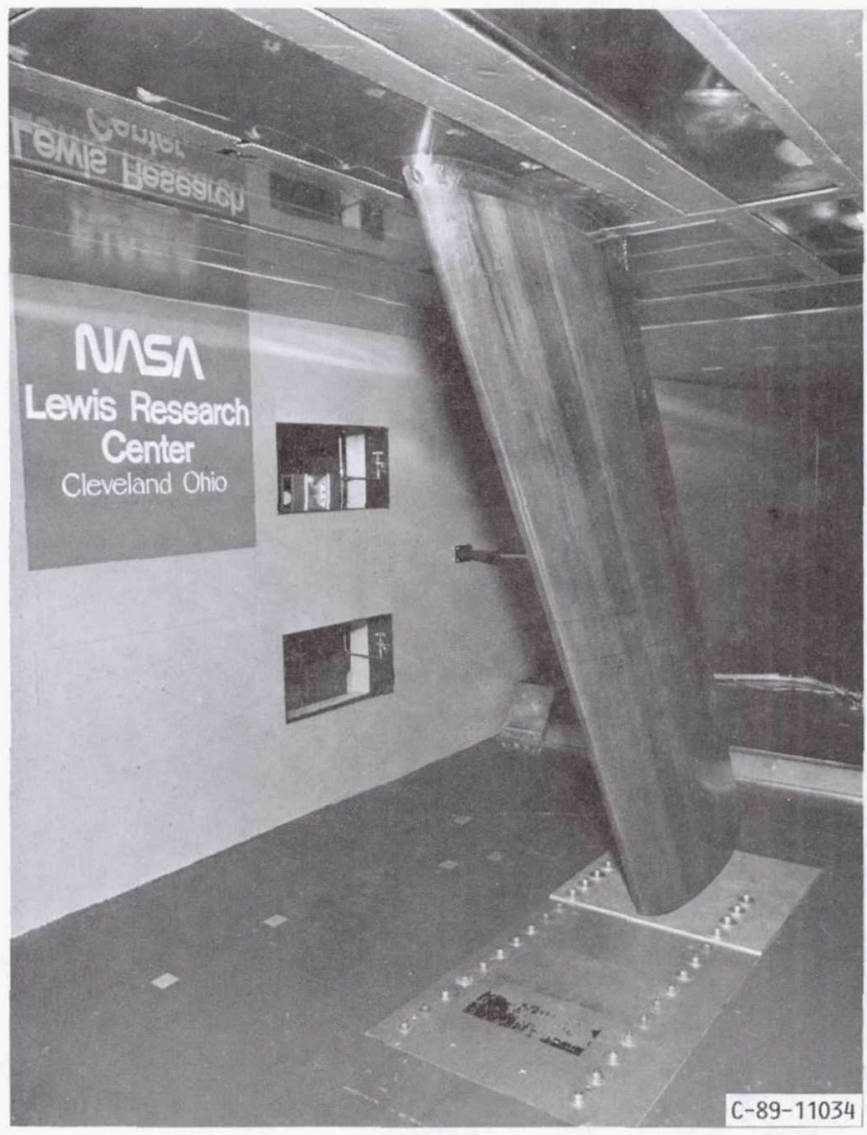

FIGURE 5. - MS-317 SWEPT WING MODEL USED TO OBTAIN ICE SHAPE TRACINGS.

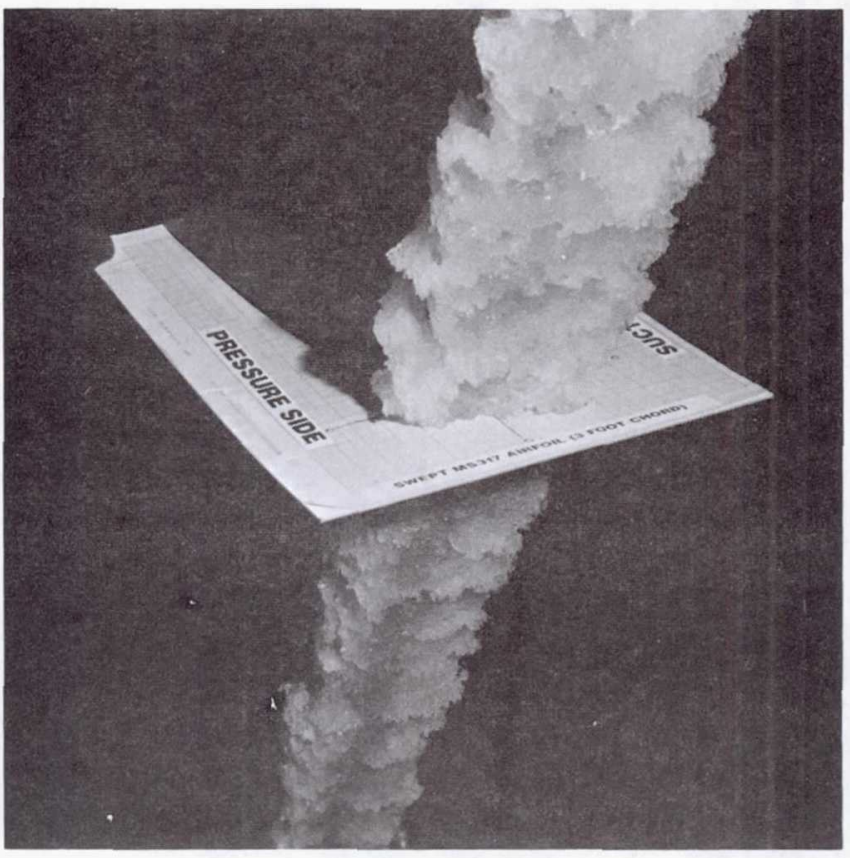

(b) GLAZE ICE AT $28^{\circ} \mathrm{F}$ AND $a=2^{\circ}$, RUN NO. 13. 


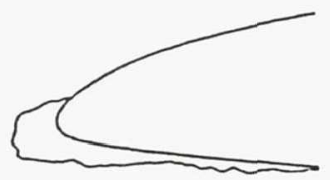

Section A

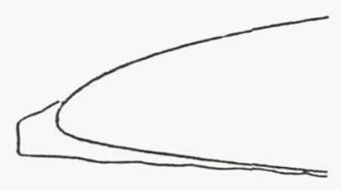

Section $\mathrm{C}_{2}$

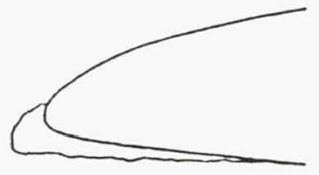

Section B

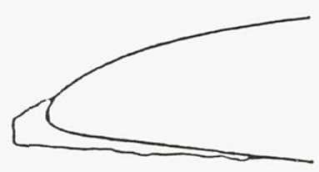

Section D

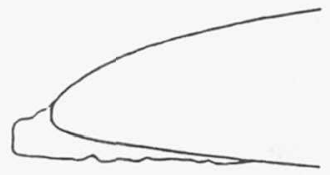

Section $C_{1}$

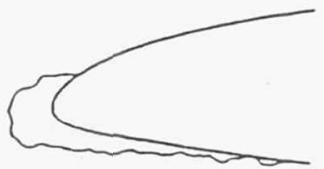

Section $E$

(a) Ice shape tracings for sections a-e.

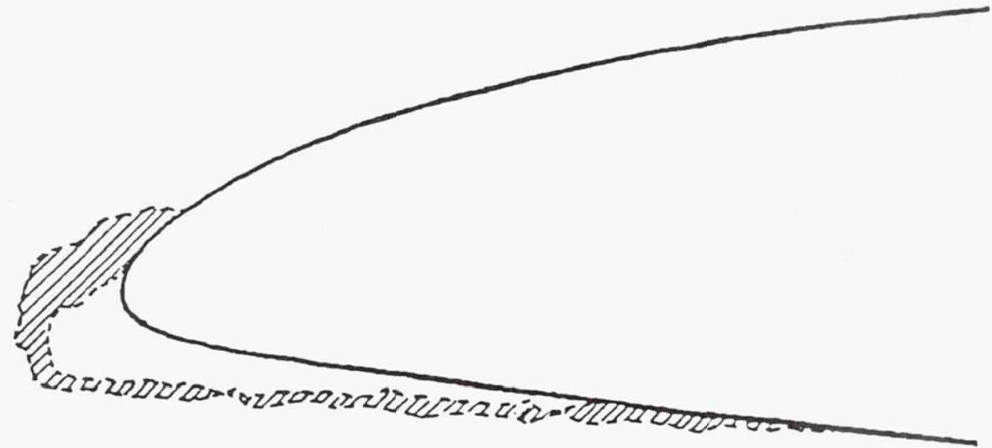

(b) Composite of ice shape tracings showing icing band.

FIGURE 7. - SPANHISE VARIATION IN ICE SHAPES FROM A 2D ICE ACCRETION. TRACINGS TAKEN AT SEVERAL LOCATIONS MLONG THE SPAN OF A BOEING 737 MODEL TESTED IN THE NASA LEHIS IRT. (TAKEN FROM REF. 15.) 


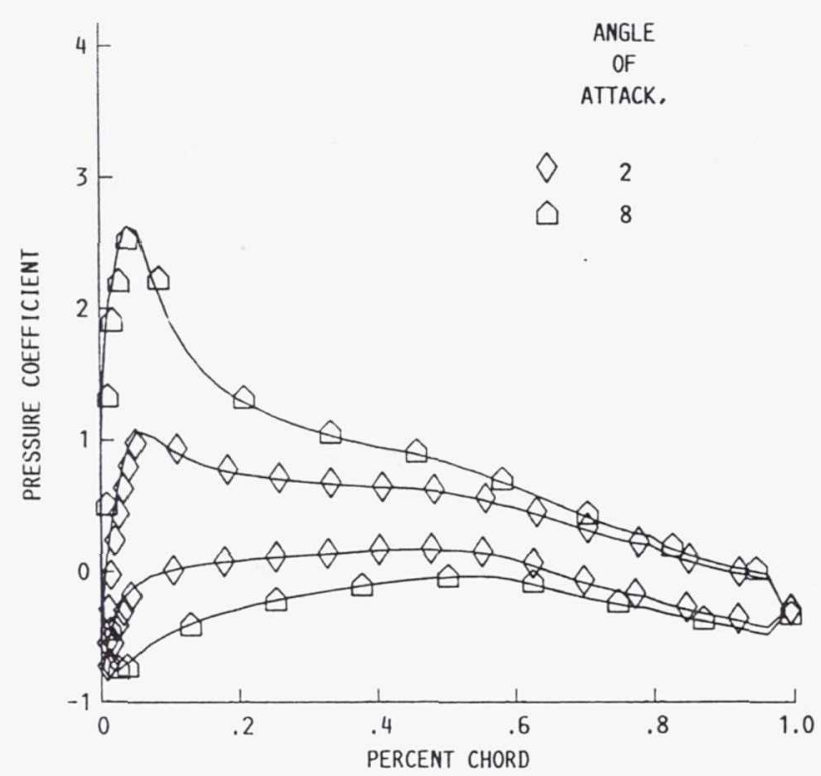

FIGURE 8. - CALCULATED PRESSURE COEFFICIENT DISTRIBUTIONS FOR MS-317 WING.

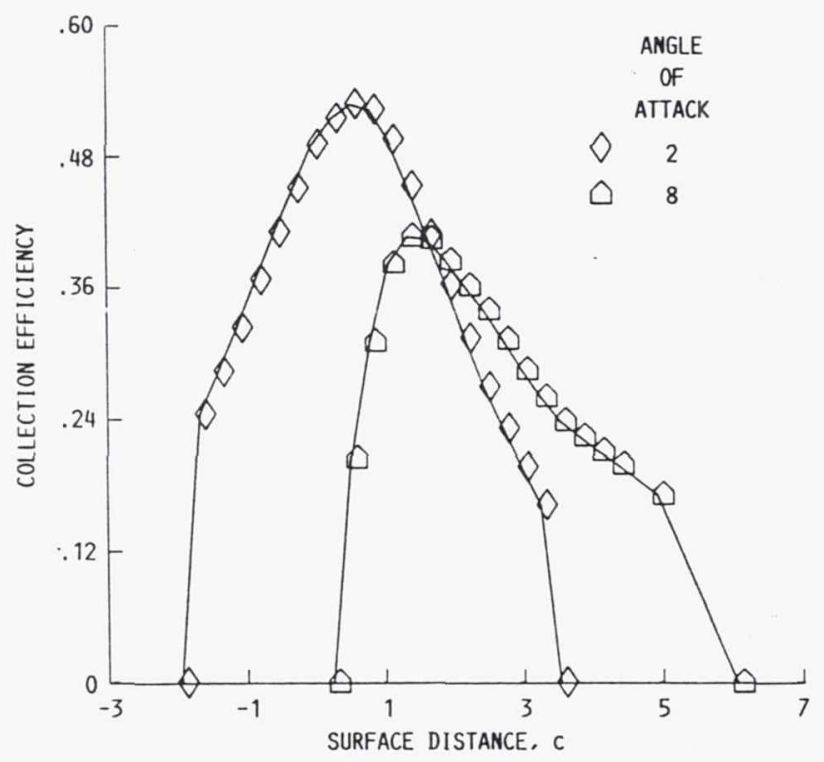

FIGURE 9. - CALCULATED COLLECTION EFFICIENCY DISTRIBUTIONS FOR MS-317 WING. ANGLE OF ATTACK, $a$, IS $2^{\circ}$ AND $8^{\circ}$.

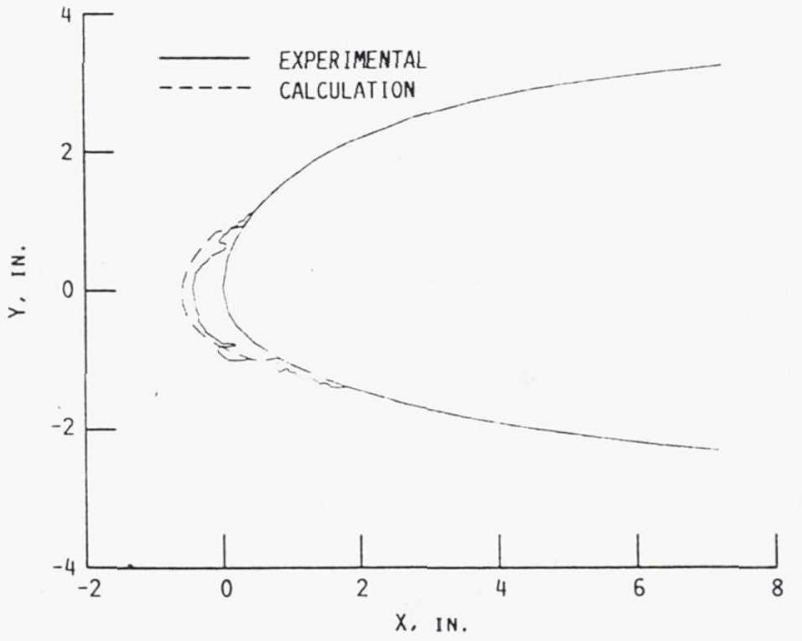

FIGURE 10. - COMPARISON OF EXPERIMENTAL ICE SHAPE TRACING WITH 3D CALCULATION FOR MS-317 WING SECTION. (RUN N0.8.)

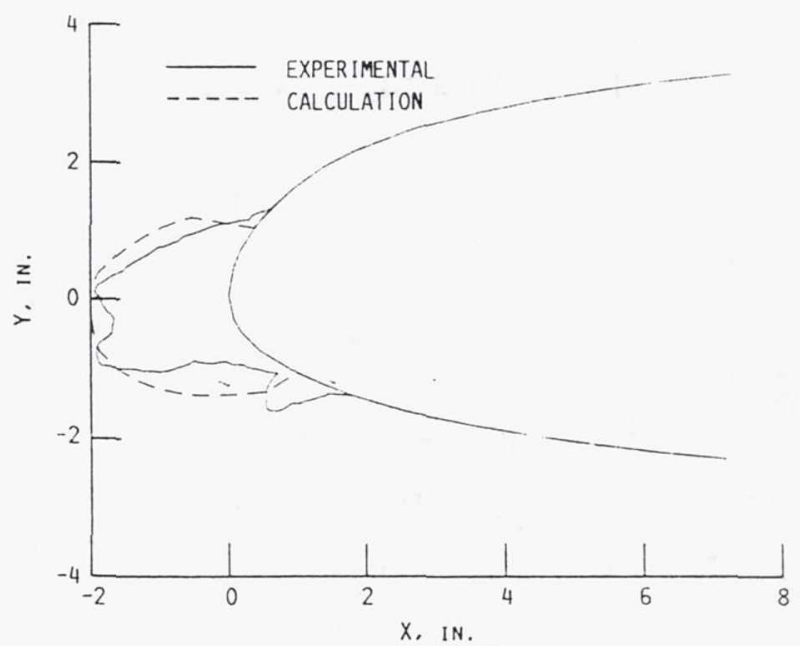

FIGURE 11. - COMPARISON OF EXPERIMENTAL ICE SHAPE TRACING WITH 3D CALCULATION FOR MS-317 WING SECTION. (RUN NO.11).

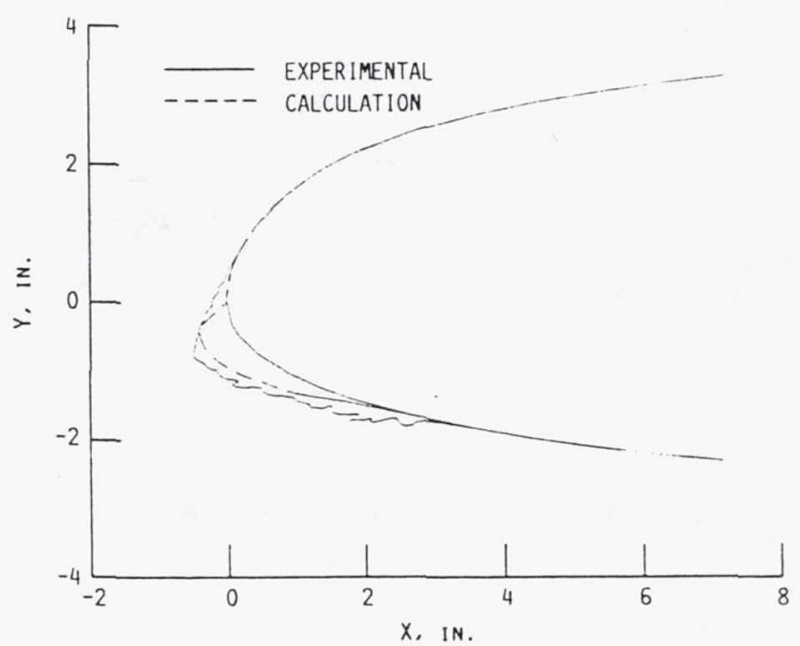

FIGURE 12. - COMPARISON OF EXPERIMENTAL ICE SHAPE TRACING WITH 3D CALCULATION FOR MS-317 WING SECTION. (RUN NO.9). 


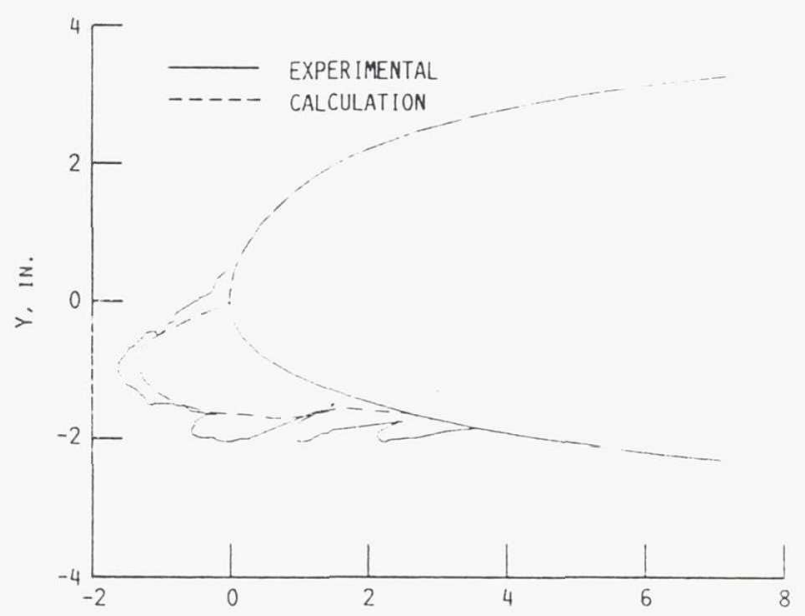

$X$, IN.

FIGURE 13. - COMPARISON OF EXPERIMENTAL ICE SHAPE TRACING WITH SD CALCULATION FOR MS-317 WING SECTION. (RUN NO. 10).

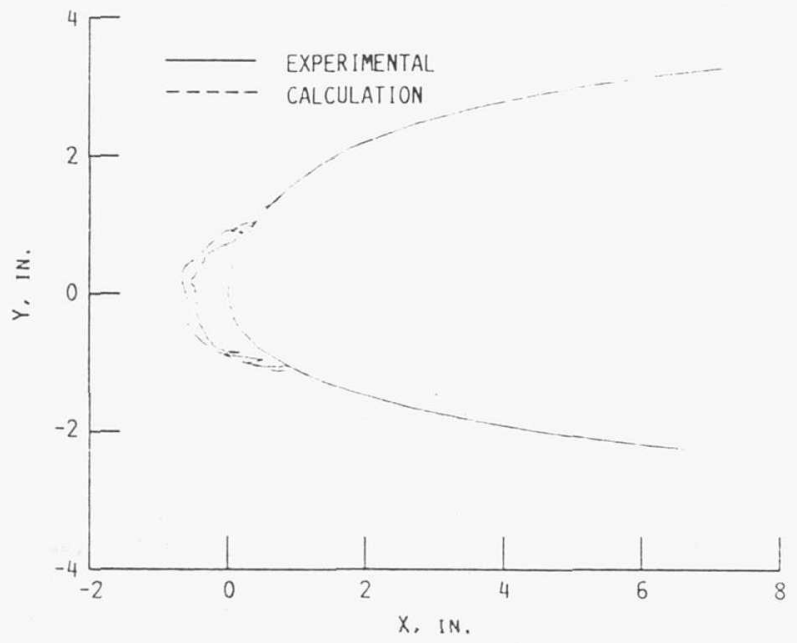

FIGURE 14. - COMPARISON OF EXPERIMENTAL ICE SHAPE TRACING WITH SD CALCULATION FOR MS-317 WING SECTION. (RUN NO .7).

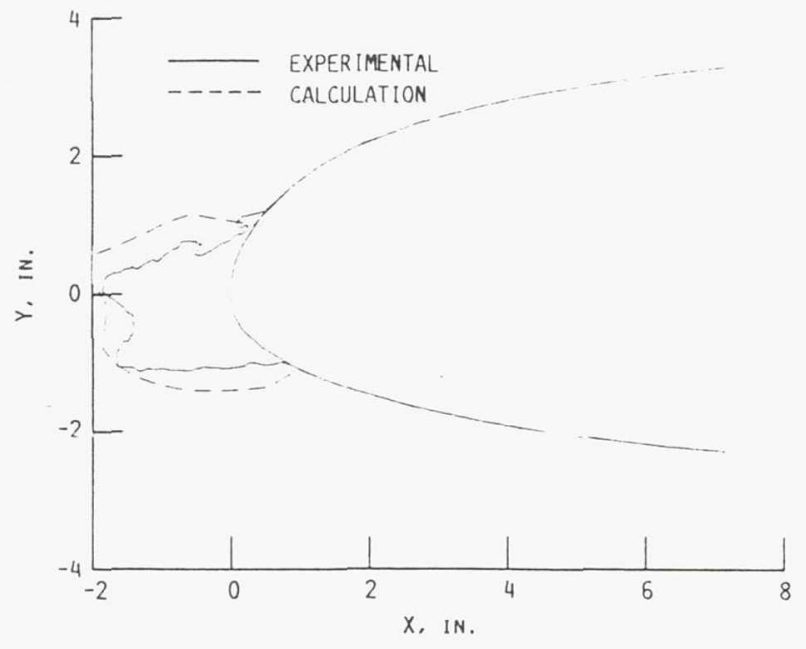

FIGURE 15. - COMPARISON OF EXPERIMENTAL ICE SHAPE TRACING WITH 3D CALCULATION FOR MS -317 WING SECTION. (RUN NOT).

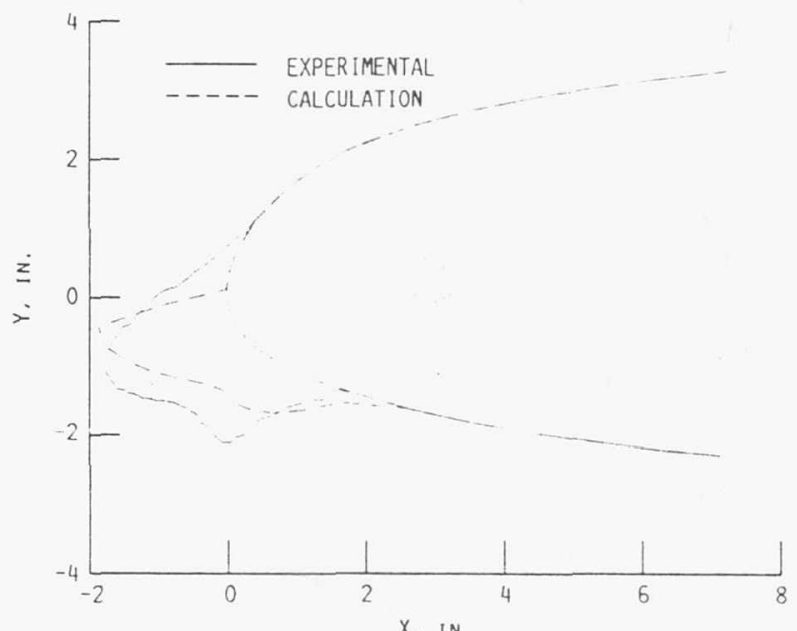

FIGURE 16. - COMPARISON OF EXPERIMENTAL ICE SHAPE TRACING WITH SD CALCULATION FOR MS-317 WING SECTION. (RUN NO.6).

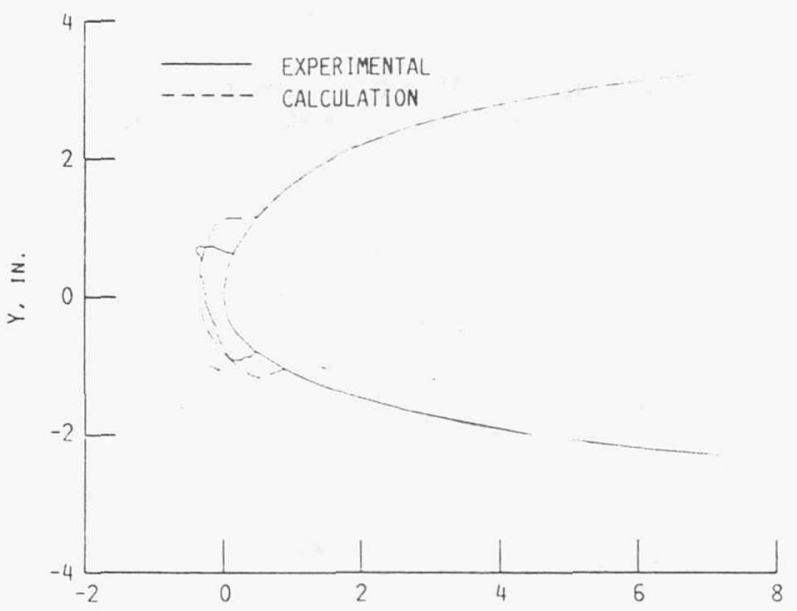

$X$, iN .

FIGURE 17. - COMPARISON OF EXPERIMENTAL ICE SHAPE TRACING WITH SD CALCULATION FOR MS-317 WING SECTION. (RUN NO.3).

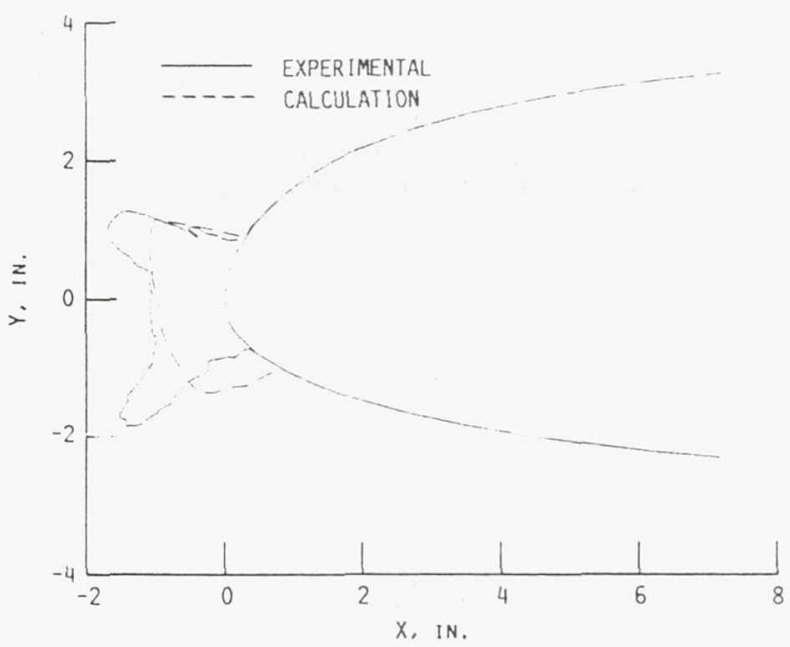

FIGURE 18. - COMPARISON OF EXPERIMENTAL ICE SHAPE TRACING WITH SD CALCULATION FOR MS-317 WING SECTION. (RUN NO.2).

21 


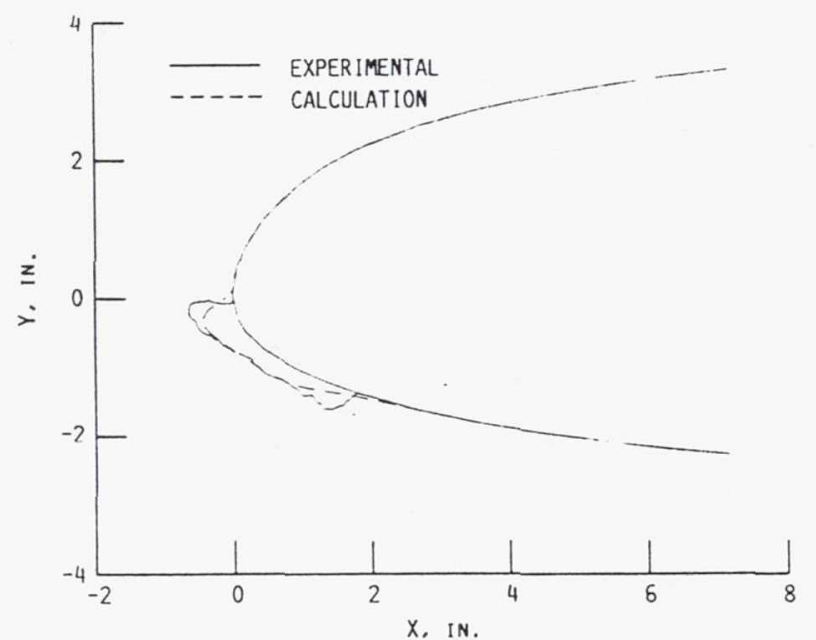

$X$, IN .

FIGURE 19. - COMPARISON OF EXPERIMENTAL ICE SHAPE TRACING WITH 3D CALCULATION FOR MS-317 WING SECTION. (RUN NO.5).

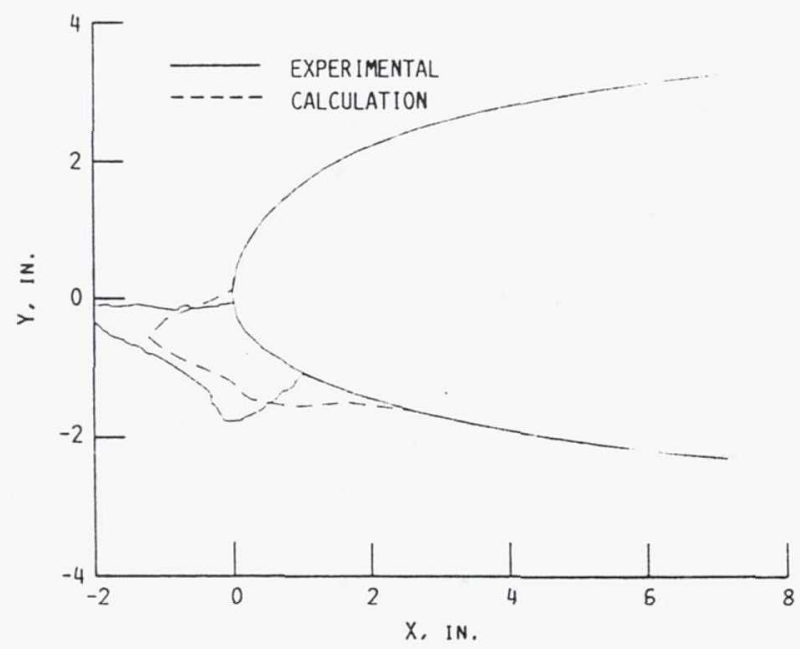

FIGURE 20. - COMPARISON OF EXPERIMENTAL ICE SHAPE TRACING WITH 3D CALCULATION FOR MS-317 WING SECTION. (RUN NO.4).

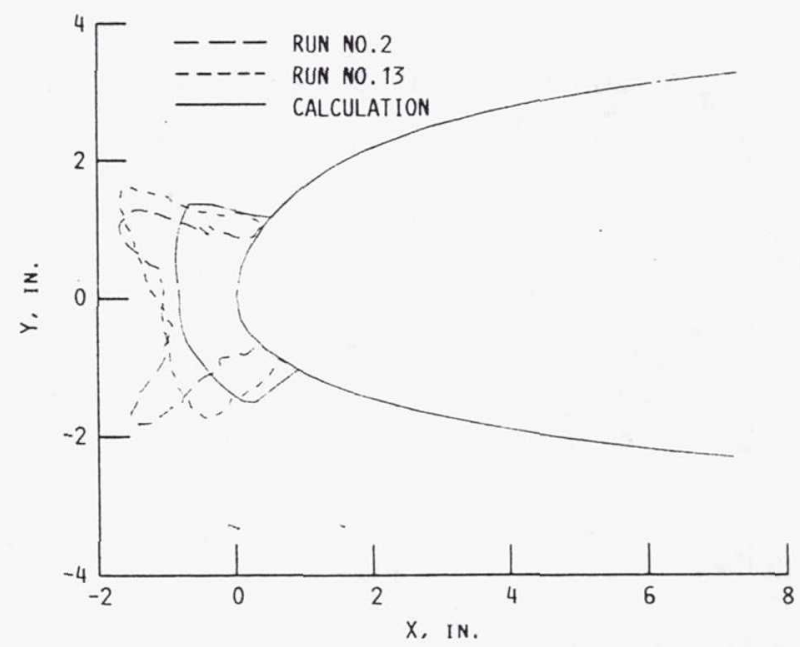

FIGURE 21. - COMPARISON OF EXPERIMENTAL ICE SHAPE TRACING WITH 3D CALCULATION FOR MS-317 WING SECTION. VARIABILITY OF THE MEASURED ICE SHAPE IS INDICATED BY COMPARISON TO TRACINGS FROM TWO RUNS AT THE SAME CONDITIONS (RUNS N0.2 AND NO.13). 


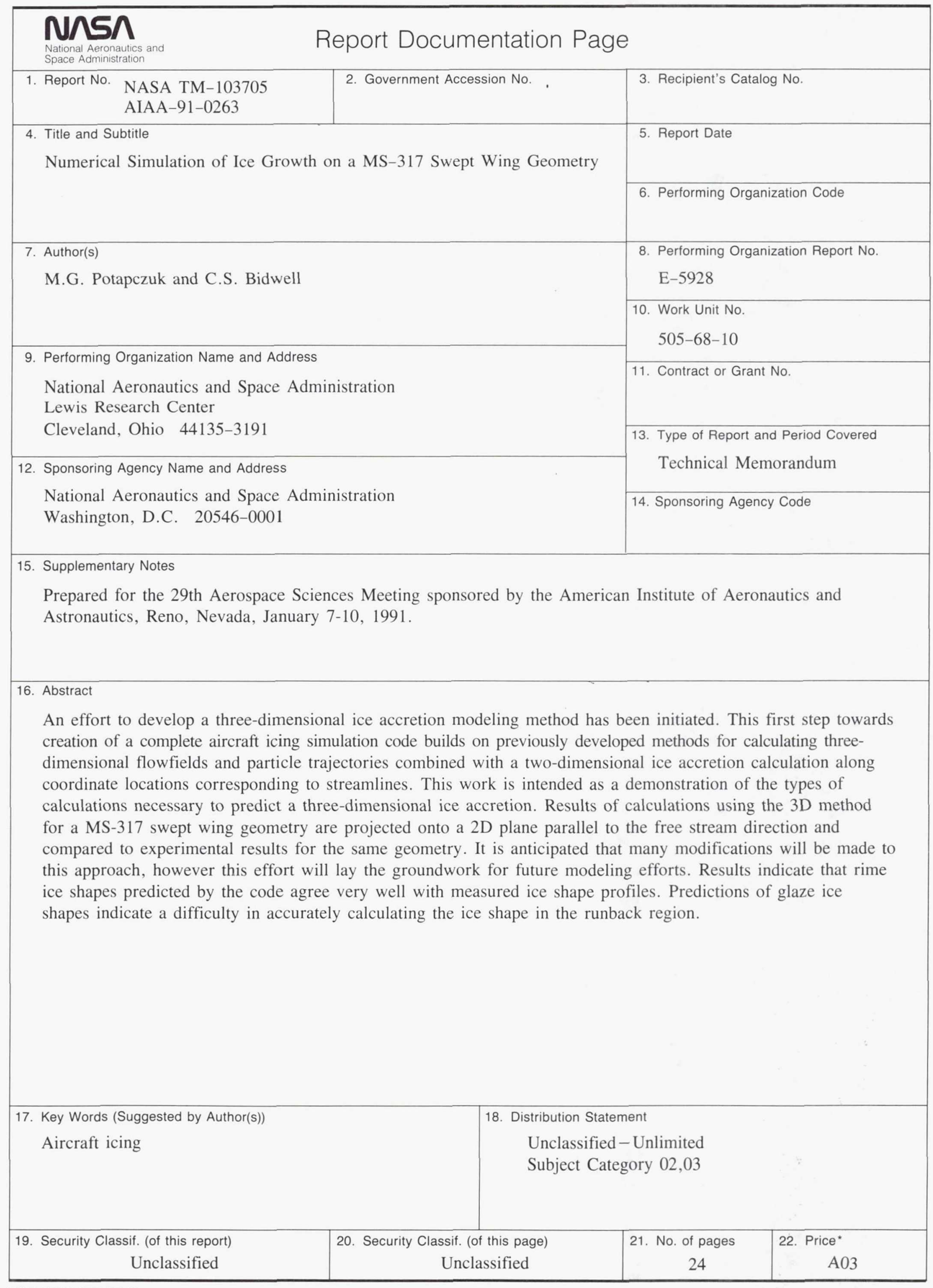

